\title{
Synthesis and Characterization of 5-Hydroxymethylfurfural from Corncob Using Solid Sulfonated Carbon Catalyst
}

\author{
Moges Admasie Mengstie $\mathbb{D}^{1}$ and Nigus Gabbiye Habtu $\mathbb{D i D}^{2}$ \\ ${ }^{1}$ Department of Industrial Chemistry, Bahir Dar University, Bahir Dar, Ethiopia \\ ${ }^{2}$ Chemical, Environmental and Process Engineering, Regional Coordinator for PHL-IL Project, \\ Feed the Future Innovation Lab Department of Chemical Engineering, Bahir Dar Institute of Technology, Bahir Dar University, \\ Bahir Dar, Ethiopia \\ Correspondence should be addressed to Moges Admasie Mengstie; moges.admasie@bdu.edu.et
}

Received 6 March 2020; Revised 1 June 2020; Accepted 13 June 2020; Published 5 August 2020

Academic Editor: Sébastien Déon

Copyright (C) 2020 Moges Admasie Mengstie and Nigus Gabbiye Habtu. This is an open access article distributed under the Creative Commons Attribution License, which permits unrestricted use, distribution, and reproduction in any medium, provided the original work is properly cited.

\begin{abstract}
5-Hydroxymethylfurfural as a versatile organic compound is considered as a promising biomass-derived product via hydrolysis followed by dehydration of lignocellulosic biomass using solid catalysts. In this study, lignocellulosic materials (corncob) were utilized to synthesize 5-hydroxymethylfurfural via solid acid catalytic conversion. The precursor of the catalyst material was chemically impregnated with $\mathrm{ZnCl}_{2}$ prior to carbonization. The solid catalyst was prepared with three different acid concentrations of $98 \%, 96 \%$, and $94 \%$ of sulfuric acid. The prepared catalyst was characterized by acid density elemental analysis, FTIR, XRD, and SEM. The maximum result of the total acid density and amount of $\mathrm{SO}_{3} \mathrm{H}$ group was recorded as $3.5 \mathrm{mmol} / \mathrm{g}$ and $0.61 \mathrm{mmol} / \mathrm{g}$, respectively, with high sulfur content of $1.87 \%$. The result from FTIR spectra of $\mathrm{BC}_{-} \mathrm{SO}_{3} \mathrm{H}_{-1}$ confirms the incorporation of $-\mathrm{SO}_{3} \mathrm{H}$ groups into the carbon material. $\mathrm{BC}-\mathrm{SO}_{3} \mathrm{H}_{-1}$ was selected based on the acid density and elemental analysis of the catalyst. The activity of the selected catalyst $\left(\mathrm{BC}-\mathrm{SO}_{3} \mathrm{H}_{-1}\right)$ was studied on the transformation of corncob to 5-hydroxymethylfurfural using biphasic solvent (water: ethyl

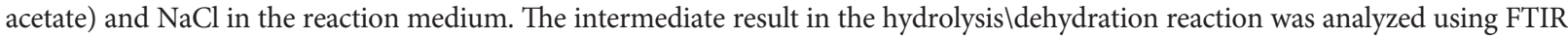
and the functional groups observed confirm the occurrence of 5-HMF in the intermediate reaction result.
\end{abstract}

\section{Introduction}

The main source of functionalized carbon skeletons for the fine chemical industry, as well as for thermal and energy transportation, is still based on the fossil-fuel reservoir [1]. However, due to the depletion of world fossil fuel reserve, the increasing of its price and its negative environmental impact has pushed the world to look for alternative renewable fossil reserve and energy sources. Biofuels in comparison to fossil fuels should be relatively cheap and rich in energy, locally produced (saving foreign currency), have environmental benefits (low greenhouse gas emission), and be producible in large quantities without impacting on food supplies.

Transformation of biomass, which is abundant and inexpensive renewable resource into fuels, chemicals, and materials precursors, has a great significance to decrease the excessive dependence on fossil resources, alleviate the energy crisis, reduce the environmental pollution, and promote the sustainable development of the whole human society [2].

Most researched sources of cellulose and hemicelluloses are bagasse, paper-pulp residue, bamboo, grain hulls, corncobs, wheat and rice straw, nutshells, rice husk, cottonseed, and wood (soft and hardwood). A corncob is a major part of the corn's waste. It is estimated that $40-50 \%$ of corn is corncob. It has been used as firewood or returned to the field. Corncob contains $69.2 \%$ cellulose, $22.8 \%$ hemicellulose, and 8\% lignin [3]. Cellulose and hemicellulose can be depolymerized into monosaccharide's like glucose, fructose, and xylose [1]. Cellulose, which is composed of $\beta$-1, 4-glycosidic bonds of D-glucose, has a highly ordered crystal structure owing to the hydrogen- 
bond network between hydroxyl groups. As a result, it is difficult to degrade and is insoluble in conventional solvents, such as water [4].

Cellulose and hemicellulose can be hydrolyzed, which on further dehydration produce furan compounds (5HMF and furfural) [5]. Among various desired compounds, 5-hydroxymethylfurfural (5-HMF) is considered as a versatile platform compound and a crucial intermediate for connecting biomass resource and fossil industry, and this is because it can be further transformed into a series of high-quality fuels such as ethyl levulinate (EL), 5-ethoxymethylfurfural (EMF), 2,5-dimethylfuran (DMF), $\mathrm{C}_{9}-\mathrm{C}_{15}$ alkane, and high-value chemicals such as levulinic acid (LA), 2,5-dihydroxymethylfuran (DHMF), 2,5-diformylfuran (DFF), and 2,5-furan dicarboxylic acid (FDCA) [2]. In addition, furfural derivatives have a wide industrial application like in oil refining, agrochemical industry, pharmaceuticals, and bioplastic (see [6]). The routes for converting cellulose into 5-HMF are illustrated in Scheme 1.

Among 5-HMF derivatives, 2,5-dimethylfuran (DMF) is particularly attractive. This is due to the high potential for mass production with high rate and higher energy content than the current market-leading bioethanol. DMF possesses a higher energy density $\left(31.5 \mathrm{MJ} \cdot \mathrm{L}^{-1}\right)$, similar to that of gasoline $\left(35 \mathrm{MJ} \cdot \mathrm{L}^{-1}\right)$ and $40 \%$ greater than that of ethanol $\left(23 \mathrm{MJ} \cdot \mathrm{L}^{-1}\right)$. In addition, higher octane number (119), lower volatility (bpt. $92-94^{\circ} \mathrm{C}$ ), lower separation energy consumption, and immiscibility with water are observed [6]. Thus, DMF is more similar to gasoline than bioethanol as a new-generation biofuel. The hydrogenolysis of 5-HMF produces 2,5-dimethylfuran (DMF) and a potentially good gasoline component, with heating value $(35 \mathrm{MJ} / \mathrm{kg})$ and boiling point $\left(93^{\circ} \mathrm{C}\right)$ higher than those of ethanol $(22.6 \mathrm{MJ} / \mathrm{kg}$ and $78^{\circ} \mathrm{C}$, respectively) [7].

Therefore, exploring alternatives to fossil fuels is of great importance. One of the most promising alternatives is biomass, owing to its abundance and renewable nature. 5Hydroxymethylfurfural is one of the most promising biomass platforms. It holds a key position in the production of liquid biofuels and biomass-derived intermediates including a vast number of chemicals. In this project, the chemical compositions of corncob can be attributed as a raw material for synthesis of 5-hydroxymethylfurfural, which is a platform chemical that can be transformed to a variety of value-added chemicals and fuels. Producing chemical precursors like 5hydroxymethylfurfural reduces or saves foreign currency due to importing and will provide a new step toward achieving renewable biomass-based chemicals and fuels platform.

In catalytic hydrolysis-dehydration of lignocellulose biomass, the action of catalyst is the limiting step in catalytic reaction process. Homogeneous catalysts such as $\mathrm{HCl}$ and $\mathrm{H}_{2} \mathrm{SO}_{4}$ have been used in hydrolysis of lignocellulose biomass. However, they suffer from problems of product separation, reactor corrosion, poor catalyst recyclability, and the need for treatment of waste effluent. On the other hand, the use of heterogeneous solid acids can solve some of these problems through the ease of product separation and good catalyst recyclability [8].

\section{Materials and Methods}

2.1. Raw Material Collection and Sample Preparation. Corncob was locally collected around Zenzelima farms, $15 \mathrm{~km}$ from Bahir Dar City, Ethiopia. The collected corncob was washed with water to remove dust and unwanted materials. It was dried in an oven at a temperature of $60^{\circ} \mathrm{C}$ for $48 \mathrm{hr}$. Then, the sample was reduced using hands and milled with milling machine and sieved to below $1 \mathrm{~mm}$ particle size. The sieved sample was kept in a closed container for use as a main raw material for the production of 5-hydroxymethylfurfural.

\subsection{Collection and Preparation of Catalyst from Bamboo} Wood. Bamboo wood (Bambusoideae), bought from furniture houses, was manually crushed and milled using milling machine. Then, the milled bamboo wood was sieved in order to obtain the desired size of bamboo wood powder $(0.4-1.5 \mathrm{~mm})$. The powder was then dried in an oven for 12 hours at $100^{\circ} \mathrm{C}$ to reduce its moisture content and stored in plastic bags for the next purpose.

\subsubsection{Chemical Activation and Carbonization of Bamboo} Wood Powder. Dried bamboo wood powder was chemically activated with zinc chloride, which can assist in lowering temperature and shortening time for activation and improving the development of inner porosity. $10-15 \mathrm{gm}$ of bamboo powder was impregnated with $20 \mathrm{wt} . \%$ zinc chloride in a beaker containing $50 \mathrm{ml} 1 \mathrm{M} \mathrm{HCl}$ solution, under mechanical agitation at $25^{\circ} \mathrm{C}$ for $15 \mathrm{hrs}$. The solid part was separated by filtration and oven-dried at $80^{\circ} \mathrm{C}$ for about $24 \mathrm{hrs}$. The dried impregnated bamboo powder was then pyrolyzed in a Nabertherm furnace at a specified temperature in an inert atmosphere. The pyrolysis process was undergone at a temperature of $450^{\circ} \mathrm{C}$ for $1 \mathrm{hr}$. Then, the obtained impregnate was discharged from the furnace and soaked first in warm $\left(100^{\circ} \mathrm{C}\right)$ aqueous $\mathrm{HCl}$ solution (5\%) for 1 hour followed by rinsing with warm distilled water $\left(50^{\circ} \mathrm{C}\right)$ for several times to remove the ash content of activated carbon until the $\mathrm{pH}$ of the washed water was neutral. Then, it was dried at $80^{\circ} \mathrm{C}$ in an oven for approximately $24 \mathrm{hrs}$.

\subsubsection{Functionalizing Chemically Activated Carbon via} Sulfonation. Functionalization of the impregnated activated carbon via sulfonation was done according to the method reported by [9]. 10-15 gm impregnated activated carbon was then functionalized by heating for 12 hours in concentrated $\mathrm{H}_{2} \mathrm{SO}_{4}$, $(100 \mathrm{ml})$ in round bottom flask at $180^{\circ} \mathrm{C}$. The sulfonation was undergone at three different concentrations of $\mathrm{H}_{2} \mathrm{SO}_{4}$, (98\%, 96\%, and 94\%). After heating, the slurry was placed in cold water and then filtered. Then the sulfonated solid catalyst was washed with warm distilled water until the wash water was neutral. Finally, the sulfonated solid catalyst was oven-dried at $80^{\circ} \mathrm{C}$ for 1 hour and the dried catalyst was packed in airtight plastic bags for the next process. The sulfonated solid carbon catalyst that was prepared at different acid concentration was represented by bamboo 


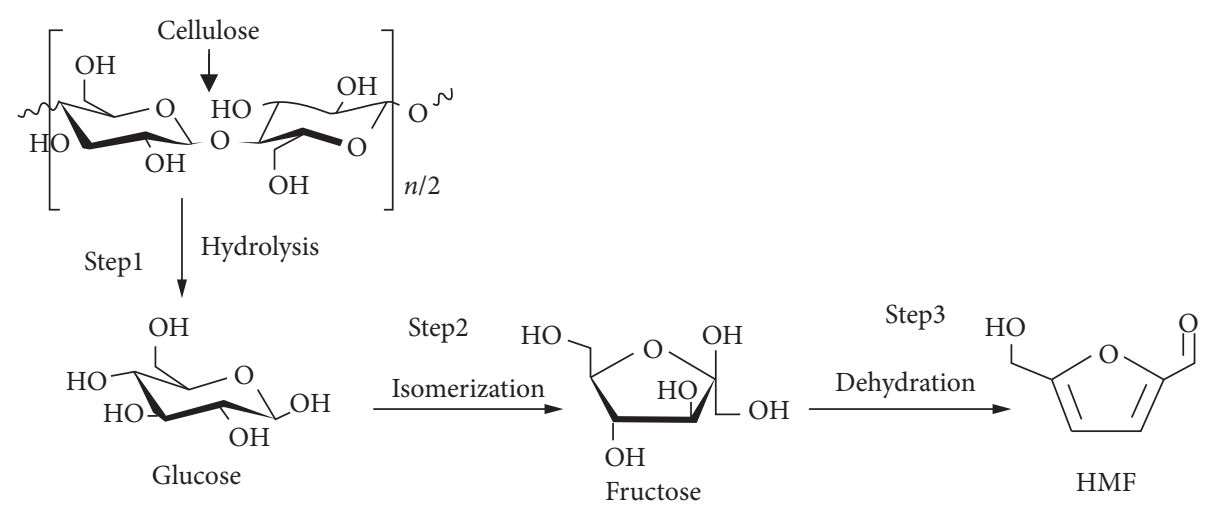

Scheme 1: Reaction mechanism for converting cellulose into 5-HMF.

carbon with no sulfonation (BC-0), bamboo carbon sulfonated with $98 \%$ concentrations of $\mathrm{H}_{2} \mathrm{SO}_{4}\left(\mathrm{BC}-\mathrm{SO}_{3} \mathrm{H}_{-1}\right)$, bamboo carbon sulfonated with $96 \%$ concentrations of $\mathrm{H}_{2} \mathrm{SO}_{4}$ (BC- $\mathrm{SO}_{3} \mathrm{H}_{-2}$ ), and bamboo carbon sulfonated with $94 \%$ concentrations of $\mathrm{H}_{2} \mathrm{SO}_{4}\left(\mathrm{BC}-\mathrm{SO}_{3} \mathrm{H}_{-3}\right)$.

\subsection{Synthesis, Separation, and Characterization of 5-HMF}

\subsubsection{Effect of Pretreatments}

(1) Delignification of Corncob. The delignification process of corncob was carried out by using the method described elsewhere [10]. The corncob powder was soaked into $20 \%$ of $\mathrm{NaOH}$ solution. The ratio between solid and solution was 1 : 10 (weight/volume). The delignification process was conducted at a temperature of $70^{\circ} \mathrm{C}$ under vigorous stirring. After the process is completed ( 12 hours), the treated corncob was separated from the liquid using a vacuum filtration system. The delignified corncob was repeatedly washed with distilled water until the $\mathrm{pH}$ of the washing solution reaches around 6.5-7. Subsequently, the treated corncob powder was dried at $110^{\circ} \mathrm{C}$ for 24 hours and stored in a plastic bag for the next process. The purpose of delignification of the corncob is to expose the cellulose for easy conversion to simple sugars.

2.3.2. Synthesis of 5-HMF. The reaction was conducted in round bottom flask batch reactor system. Corncob powder $(5 \mathrm{~g})$ was added to the round bottom flask containing sulfonated porous carbon catalyst $(0.5 \mathrm{~g}), 20 \mathrm{wt} . \% \mathrm{NaCl}$, and water-ethyl acetate biphasic solvent at ratios of $1: 2$. The flask was equipped with a reflux condenser and the reaction mixture was stirred and heated at the desired temperature of $\left(180^{\circ} \mathrm{C}\right)$ for a reaction time (3.1 hours). Then the distillate was collected to the extraction flask.

2.3.3. Separation and Characterization of 5-HMF. The organic phase containing 5-HMF layer was separated using a rotary evaporator. The product separated from the solvent was analyzed with FTIR in order to identify attached functional group on 5-hydroxymethylfurfural.

\section{Results and Discussion}

3.1. Characterization of Corncob and Catalyst. In this chapter, the prepared catalyst was characterized by using, FTIR, XRD, SEM, TGA, and elemental analysis. The total acid densities of the catalysts were also measured using back titration and direct titration for $\mathrm{SO}_{3} \mathrm{H}$ acid density. The intermediate product synthesized from delignified corncob (5-HMF) was characterized with FTIR spectroscopy.

3.1.1. Proximate Composition of Corncob. The proximate analysis of raw corncob (moisture content, volatile matter, fixed carbon, and ash content) was determined using ASTM D1762-84. The measurement was done three times and the average was taken to increase the accuracy.

Table 1 shows the result of proximate analysis of raw corncob. The results were in general agreement with other results reported elsewhere $[3,11,12]$. The low ash content obtained in this study may be due to the use of different corncob species of varieties and treatment conditions [11]. The corncob having higher moisture content needs more heat for moisture vaporization. Ash is a measure of inorganic impurities in the corncob and in this study the low in ash content helps to decrease sludge formation during the synthesis of 5-HMF. Having low moisture content is suggested for the catalytic conversion process due to the fact that high moisture content may increase water content in the reaction, which hinders the catalytic activity of the catalyst by interacting with hydrogen bond of the cellulose of corncob with the water molecule rather than with the catalyst [13].

3.1.2. Chemical Composition of Corncob. The chemical composition of corncob was determined using the method described by [14]. Table 2 shows the result of chemical composition of raw corncob and $\mathrm{NaOH}$-treated corncob. The results of this study are in comparable range with values in some literatures reported elsewhere $[2,3,15]$. The low value of lignin content $(19.88 w / w \%)$ is important for easy hydrolysis of the hollow-cellulose (cellulose and hemicellulose). Because the corncob contains high cellulose, this material is suitable as the raw material for 5-hydroxymethylfurfural production [10]. 
TABle 1: Proximate composition of raw corncob.

\begin{tabular}{lc}
\hline Property & Value (wt.\%) \\
\hline Ash content & 0.73 \\
Moisture content & 5.4 \\
Volatile matter & 81.2 \\
Fixed carbon content & 12.67 \\
\hline
\end{tabular}

TABle 2: Chemical composition of raw corncob.

\begin{tabular}{lcc}
\hline Chemical composition & $\begin{array}{c}\text { Corncob } \\
(w / w \%)\end{array}$ & $\begin{array}{c}\mathrm{NaOH} \text {-treated corncob } \\
(w / w \%)\end{array}$ \\
\hline Extractives & 5.8 & 3.21 \\
Cellulose & 52.64 & 59.83 \\
Hemicellulose & 17.81 & 17.08 \\
Lignin & 23.75 & 19.88 \\
\hline
\end{tabular}

\subsection{Raw Bamboo and Catalyst Characterization}

3.2.1. Proximate Analysis of Raw Bamboo Wood. Proximate analysis was required to have information about moisture, volatile matter, and ash as well as fixed carbon contents of bamboo wood. These properties are relevant to the thermal conversion of any biomass material into energy [11]. The proximate analysis of the raw bamboo dust (moisture content, volatile matter, fixed carbon, and ash content) was determined using ASTM D1762-84. The measurement was done three times and the average value was taken to increase the accuracy.

Table 3 shows the proximate analysis results of the raw bamboo. The bamboo sample was high in volatiles and fixed carbon but low in ash content. This high volatile matter content was anticipated because of the organic nature of the material used. The contents of volatile matter in biomass materials are usually high due to the organic nature of the biomass [11]. The bamboo supplied had a moisture content of about $4.6 \%$, which is a well-tolerated value for the production of activated carbon. The proximate analysis reported here is in general agreement with previous studies [16]. Biomass with higher fixed carbon content has higher activated carbon yield and higher surface area for attachment of the sulfonated group during sulfonation reaction. The low ash content would result in minimal effects of inorganic impurities on pore development during activation process. Previous studies suggested that suitable activated carbon should be low in ash but rich in carbon and volatiles [17]. High ash content is undesirable for activated carbon since it reduces the mechanical strength of carbon and affects adsorptive capacity [18].

\subsubsection{Ultimate Analysis (CHNS) of the Catalyst.} Ultimate analysis is used to determine the elemental composition of the sample. It is based on the principle of Dumas method, which involves the complete and instantaneous oxidation of the sample by flash combustion.

Investigation on ultimate or elemental analysis of the catalyst and bamboo carbon was done and the results are shown in Table 4 . The results confirm that the bamboo carbon (BC-0) has higher carbon content than the catalyst
Table 3: Proximate analysis of raw bamboo wood powder.

\begin{tabular}{lc}
\hline Property & Value (\%) \\
\hline Ash content & 1.4 \\
Moisture content & 4.6 \\
Volatile matter & 80.62 \\
Fixed carbon content & 17.98 \\
\hline
\end{tabular}

TABLE 4: Elemental analysis of the catalyst and bamboo carbon.

\begin{tabular}{lcccc}
\hline Sample & $\mathrm{N}(\%)$ & $\mathrm{C}(\%)$ & $\mathrm{H}(\%)$ & $\mathrm{S}(\%)$ \\
\hline $\mathrm{BC}-0$ & 0.15 & 76.34 & 3.16 & - \\
$\mathrm{BC}^{-} \mathrm{SO}_{3} \mathrm{H}_{-1}$ & 0.25 & 60.32 & 2.53 & 1.87 \\
$\mathrm{BC}^{-\mathrm{SO}_{3} \mathrm{H}_{-2}}$ & 0.28 & 61.21 & 2.23 & 1.63 \\
$\mathrm{BC}^{-\mathrm{SO}_{3} \mathrm{H}_{-3}}$ & 0.32 & 63.42 & 2.61 & 1.52 \\
\hline
\end{tabular}

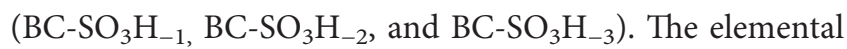
analysis also shows that the catalyst prepared by sulfonation of the bamboo carbon with $98 \% \mathrm{H}_{2} \mathrm{SO}_{4}$ has high sulfur content than the catalyst prepared by sulfonation of the bamboo carbon with $96 \%$ and $94 \% \mathrm{H}_{2} \mathrm{SO}_{4}$, which agrees with acid density of the catalysts discussed above. In addition to this, the elemental analysis shows that the increase in sulfur content with increasing acid concentration confirms increasing of active sites in the catalyst, resulting in increasing total acid density and catalytic activity. As shown in Table 4 , the result shows an increase of nitrogen content with sulfonation. It indicates that the volatilization of nitrogen during sulfonation is very low.

3.2.3. Acid Density of the Catalyst. The total acidity groups, as well as the amount of $\mathrm{SO}_{3} \mathrm{H}$ group, were determined by using back titration for total acid density and direct titration for $\mathrm{SO}_{3} \mathrm{H}$ acid density following the method reported in the literature [9].

The total acid density and amount of $-\mathrm{SO}_{3} \mathrm{H}$ group for the catalyst results are presented in Table 5. The total acid density and amount of $-\mathrm{SO}_{3} \mathrm{H}$ group which are incorporated into the carbon were increased as the concentration of the sulfonation agent, $\mathrm{H}_{2} \mathrm{SO}_{4}$, was increased. As can be seen in Table 5 , total acid density and amount of $-\mathrm{SO}_{3} \mathrm{H}$ groups were not observed in the carbon without sulfonation.

3.2.4. Fourier Transform Infrared Spectroscopy. The FTIR spectra of the sulfonated solid carbon catalyst, which was prepared at a different concentration of sulfuric acid, are presented in Figures 1(a)-1(d). In Figure 1(a), there is a broad peak between $3600 \mathrm{~cm}^{-1}$ and $3000 \mathrm{~cm}^{-1}$ attributable to aliphatic C-H bond, aromatic $\mathrm{C}-\mathrm{H}$ bond, $\mathrm{O}-\mathrm{H}$ bond in a carboxylic acid group, and $\mathrm{O}-\mathrm{H}$ bond in a phenyl group [19]. An additional peak at $1624 \mathrm{~cm}^{-1}$ was $\mathrm{C}=\mathrm{O}$ stretching vibration peak.

In Figure 1(b), the occurrence of peaks at $1027-1061 \mathrm{~cm}^{-1}$ was attributed to the symmetric $\mathrm{S}=\mathrm{O}$ stretching vibration. This band implies the presence of $\mathrm{SO}_{3} \mathrm{H}$ groups and confirms the incorporation of sulfonic groups onto the carbon matrix after sulfonation. As seen from Figure 1(a), the aliphatic $\mathrm{C}-\mathrm{H}$ bond, aromatic $\mathrm{C}-\mathrm{H}$ bond, $\mathrm{O}-\mathrm{H}$ bond in a carboxylic acid group, and $\mathrm{O}-\mathrm{H}$ bond in a 
TABLE 5: Total acid density and amount of $-\mathrm{SO}_{3} \mathrm{H}, \mathrm{COOH}$, and $\mathrm{OH}$ groups of catalyst.

\begin{tabular}{lccc}
\hline Sample type & Total acid density $(\mathrm{mmol} / \mathrm{g})$ & The amount of $-\mathrm{SO}_{3} \mathrm{H}$ group $(\mathrm{mmol} / \mathrm{g})$ & $\mathrm{COOH}$ and $\mathrm{OH}(\mathrm{mmol} / \mathrm{g})$ \\
\hline${\mathrm{BC}-\mathrm{SO}_{3} \mathrm{H}_{-1}}_{\mathrm{BC}-\mathrm{SO}_{3} \mathrm{H}_{-2}}$ & 3.5 & 0.61 & 2.89 \\
$\mathrm{BC}_{-} \mathrm{SO}_{3} \mathrm{H}_{-3}$ & 3.43 & 0.45 & 2.98 \\
\hline
\end{tabular}

Note: $\mathrm{BC}-0$ is carbon catalyst without sulfonation; $\mathrm{BC}-\mathrm{SO}_{3} \mathrm{H}_{-1}, \mathrm{BC}-\mathrm{SO}_{3} \mathrm{H}_{-2}$, and $\mathrm{BC}-\mathrm{SO}_{3} \mathrm{H}_{-3}$ are carbon catalysts sulfonated with different concentrations of $\mathrm{H}_{2} \mathrm{SO}_{4}(98 \%$, 96\%, and 94\%), respectively.

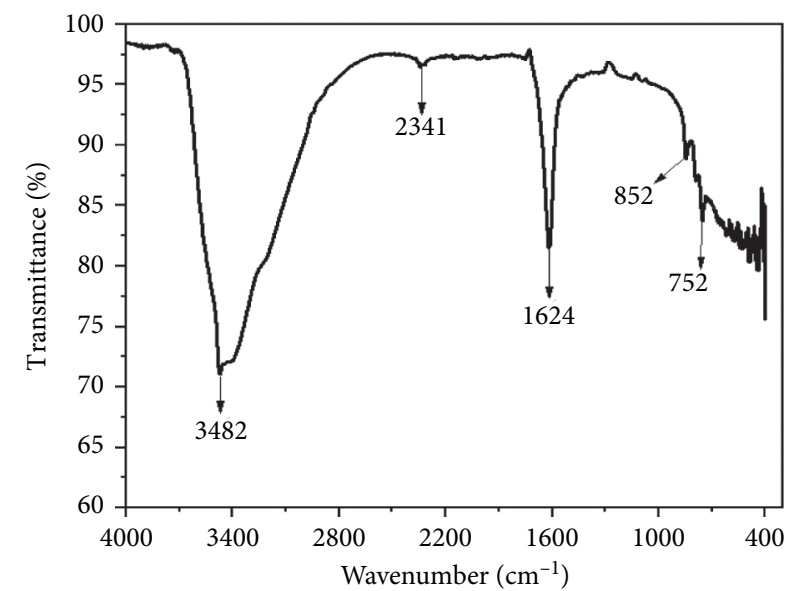

(a)

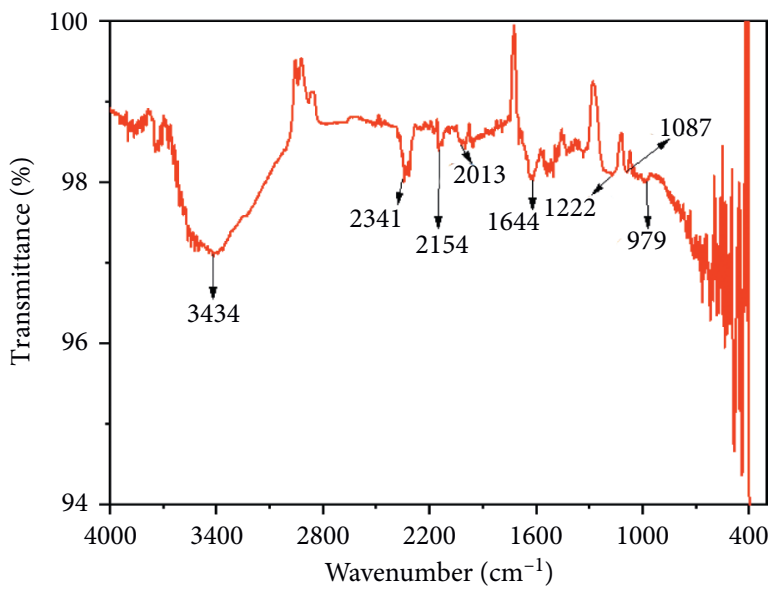

(c)

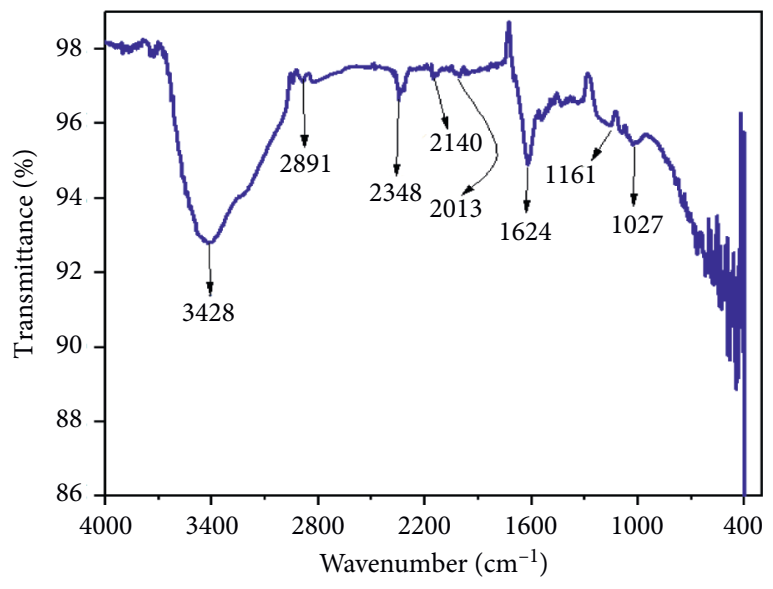

(b)

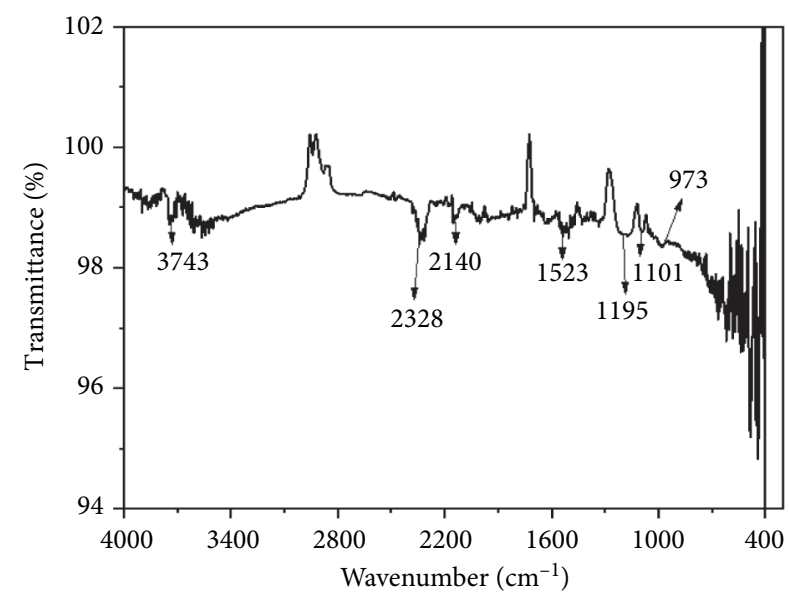

(d)

FIGURE 1: FTIR spectrum of sulfonated carbon catalysts

(a) $\mathrm{BC}_{-0}$, (b) $\mathrm{BC}-\mathrm{SO}_{3} \mathrm{H}_{-1}$, (c) BC- $\mathrm{SO}_{3} \mathrm{H}_{-2}$, and (d) $\mathrm{BC}-\mathrm{SO}_{3} \mathrm{H}_{-3}$.

phenol group have also been seen in the spectra of $\mathrm{BC}$ $\mathrm{SO}_{3} \mathrm{H}_{-1}$ (sulfonated carbon catalyst). The FTIR of BC$\mathrm{SO}_{3} \mathrm{H}_{-1}$ also contains a peak at $1631 \mathrm{~cm}^{-1}$ which is assigned to the stretching vibration of $\mathrm{C}=\mathrm{C}$ groups in the aromatic and $1242 \mathrm{~cm}^{-1}$ is C-O vibration.

Figure 1 (c) has weak peaks at $1051 \mathrm{~cm}^{-1}$ (symmetric $\mathrm{S}=\mathrm{O}$ stretching) and $1244 \mathrm{~cm}^{-1}$ (C-O) and medium peak at $1658 \mathrm{~cm}^{-1}(\mathrm{C}=\mathrm{C})$. From $(\mathrm{c})$, the band intensity that shows the aliphatic $\mathrm{C}-\mathrm{H}$, aromatic $\mathrm{C}-\mathrm{H}$ bond, $\mathrm{O}-\mathrm{H}$ bond in the carboxylic acid group, and $\mathrm{O}-\mathrm{H}$ bond in the spectra becomes weak, which agrees with the fact that an acid density of the catalyst was decreased as the concentration of sulfuric acid decreased from $98 \%$ to $96 \%$. The bands that show the present
$\mathrm{SO}_{3} \mathrm{H}$ and the aliphatic $\mathrm{C}-\mathrm{H}$, aromatic $\mathrm{C}-\mathrm{H}$ bond, $\mathrm{O}-\mathrm{H}$ bond in the carboxylic acid group, and $\mathrm{O}-\mathrm{H}-$-bond in (b) and some amount in (c) are not visible in the FTIR spectrum of (d). This was due to the fact that the total acid density and amount of $\mathrm{SO}_{3} \mathrm{H}$ in the sample (d), (i.e., carbon catalyst in which bamboo carbon was sulfonated with $94 \% \mathrm{H}_{2} \mathrm{SO}_{4}$ ), were much smaller than samples (b) and (c).

The overall FTIR analysis suggests that the carbon-based catalysts consist of polycyclic aromatic carbon sheets containing $\mathrm{SO}_{3} \mathrm{H}, \mathrm{COOH}$, and $\mathrm{OH}$ moieties, in agreement with the research report for acid-functionalized incomplete carbonized sugars catalyst $[4,20]$. From this perspective, we can deduce that as the acid concentration increases for 
sulfonation purpose, the total acid density and amount of $\mathrm{SO}_{3} \mathrm{H}$ group could increase and affect the reaction medium during the hydrolysis\dehydration process.

3.2.5. $X$-Ray Diffraction (XRD). The XRD patterns shown in Figure $2\left(\mathrm{BC}-\mathrm{SO}_{3} \mathrm{H}_{-1}\right.$ and $\mathrm{BC}-\mathrm{SO}_{3} \mathrm{H}_{-2}$ and $\mathrm{BC}-\mathrm{SO}_{3} \mathrm{H}_{-3}$ ) exhibit similar patterns. In both cases, typical crystal diffraction peaks were not seen. The width and weak diffraction peak around $2 \theta=19.46^{\circ}-23.34^{\circ}$ in all patterns implied that the structures of both samples were amorphous. This was due to the fact that the cellulose and hemicellulose chains of branches may dehydrate. Lignin may polymerize or rearrange. Crystal structure decomposed and amorphous hydrocarbon structure was detected.

3.2.6. Thermogravimetric Analysis. The thermal behavior of $\mathrm{BC}-0$ and $\mathrm{BC}-\mathrm{SO}_{3} \mathrm{H}_{-1}$ catalysts was determined by TGA as shown in Figure 3. Thermogravimetric analysis (TGA) was performed in a thermogravimetric analyzer (TA Instruments, SDT Q600 V20.9 Build 20) using temperature programming from 35 to $800^{\circ} \mathrm{C}$ at the heating rate of $20^{\circ} \mathrm{C} / \mathrm{min}$ to which the sample was heated under a $2 \mathrm{~mL} / \mathrm{min}$ flow of nitrogen. The TGA result of bamboo carbon in Figure 3 indicates that the initial weight loss begins at a temperature around $55^{\circ} \mathrm{C}$. The weight loss of the carbon-based catalysts sample can be associated with the decomposition of the functional groups as well as the carbon structure. Weight loss at $100-125^{\circ} \mathrm{C}$ is associated with the evaporation of moisture for bamboo carbon. Similarly, the marginal weight loss occurred for sulfonated catalyst $\left(\mathrm{BC}-\mathrm{SO} 3 \mathrm{H}_{-1}\right)$ sample at $100-125^{\circ} \mathrm{C}$ due to desorption of water vapors. From 135 to $440^{\circ} \mathrm{C}$, there was a steady change in weight percentage of bamboo carbon. From 440 to $800^{\circ} \mathrm{C}$ for BC- 0 , a continuous weight loss can be observed from a plot which refers to thermal decomposition of weak acidic sites and strong Bronsted acidic sites [21]. For the overall analysis, the sample lost about $8 \%$ of its weight at $800^{\circ} \mathrm{C}$.

For sulfonated carbon catalyst, it can be observed that it can bear temperatures up to $465^{\circ} \mathrm{C}$; as can be seen from the plot, the weight of the catalyst drops slightly plateaued from 125 to $465^{\circ} \mathrm{C}$, which can be interpreted to be due to the decomposition of the $\mathrm{SO}_{3} \mathrm{H}$ groups. For sulfonated carbon catalyst, loss of weak and strong Bronsted acidic sites was observed to be from 465 to $800^{\circ} \mathrm{C}$.

3.2.7. Scanning Electron Microscopy (SEM). The morphology and surface structure of the carbonized bamboo dust after sulfonation are shown in Figure 4. Scanning electron microscopy (SEM) has been extensively used to characterize the microstructure of bamboo carbon and sulfonated bamboo carbon catalyst. The surface morphology, such as the surface shape, pattern, and feature of the selected bamboo carbon and sulfonated carbon catalyst, was observed using JEOL JSM-IT300 SEM attached with Energy Dispersive X-ray (EDX).

SEM images for both $\mathrm{BC}-0$ and $\mathrm{BC}-\mathrm{SO}_{3} \mathrm{H}_{-1}$ catalyst suggested that the white dots represent the inorganic composition [21]. It can be revealed from the images that activated carbon possesses irregular compact structure, while sulfonated catalyst particles appear to be like smooth surfaces. From these images, it can be seen that the sulfonated catalyst $\left(\mathrm{BC}-\mathrm{SO}_{3} \mathrm{H}_{-1}\right)$ consisted mainly of aggregates of carbonaceous micropores that had diameters of several $\mu \mathrm{m}$. The white spots of the mesoporous catalyst were partially destroyed after treatment through sulfonation. When bamboo carbon was sulfonated with $\mathrm{H}_{2} \mathrm{SO}_{4}$, a morphological change occurred and the resulting bamboo carbon sulfonated catalyst had micropores due to sulfonation. It is believed that, during the sulfonation process, the carbon tubes, which are not strongly bound, are arranged into amorphous carbon or burnt away [22]. The morphological difference between the catalyst and bamboo carbon implies the incorporation of $-\mathrm{SO}_{3} \mathrm{H}$ in bamboo carbon.

3.3. Performance of $\mathrm{BC}-\mathrm{SO}_{3} \mathrm{H}_{-1}$ Catalyst for Conversion of Corncob to HMF. Further investigation on the activity of the catalyst was performed in the synthesis of HMF from corncob. The synthesized activated and sulfonated carbon catalyst was utilized for synthesis of HMF. Based on the acid density, elemental analysis, and FTIR analysis, the best catalyst $\left(\mathrm{BC}-\mathrm{SO}_{3} \mathrm{H}_{-1}\right)$ was chosen for suitable conversion of corncob to $\mathrm{HMF}$. The hydrolysis 1 dehydration reaction was carried out using a $250 \mathrm{ml}$ capacity round bottom flask reactor which was equipped with a condenser, magnetic stirrer, and temperature probes. The magnetic stirrer's rotational speed, reaction time, and temperature were adjusted to the desired conditions. The result obtained was confirmed via FTIR test.

\subsubsection{Characterization Results of the Intermediate Product} Using FTIR. The product was characterized and confirmed by using FTIR spectroscopy. Samples were measured on Spectrum 65 FTIR (PerkinElmer) in the range of $4000-400 \mathrm{~cm}^{-1}$ using unwarp salt plates. The HMF's characteristic FTIR absorptions were associated with the $-\mathrm{OH}$, $\mathrm{C}-\mathrm{H}, \mathrm{C}=\mathrm{C}$, and $\mathrm{C}=\mathrm{C}-\mathrm{H}$ stretching vibrations. Figure 5 depicts FTIR spectra of HMF that was synthesized from corncob using solid sulfonated carbon catalyst. FTIR spectrum of HMF appeared as broader and sharper bands in the region. These bands are attributed to the presence of free alcoholic $\mathrm{O}-\mathrm{H}$ groups stretching vibration at $3,400 \mathrm{~cm}^{-1}$ in 5-HMF, aldehyde $\mathrm{C}-\mathrm{H}$ at 2,850 and $2,930 \mathrm{~cm}^{-1}$, aldehyde $\mathrm{C}=\mathrm{O}$ stretching at $1,675 \mathrm{~cm}^{-1}$, aromatic $\mathrm{C}=\mathrm{C}$ stretching at $1,520 \mathrm{~cm}^{-1}$, and furan ring ether asymmetric stretching C-O-C at $1,190 \mathrm{~cm}^{-1}$, which was confirmed by [23]. The band at $1667 \mathrm{~cm}^{-1}$ and $1221 \mathrm{~cm}^{-1}$ indicates the presence of carbonyl group $(\mathrm{C}=\mathrm{O})$ and carbon-carbon double bond $(\mathrm{C}=\mathrm{C})$, respectively, and alcoholic $\mathrm{C}-\mathrm{O}$ stretching at $1,025 \mathrm{~cm}^{-1}$ was observed [24]. The peaks between 1700 and $1500 \mathrm{~cm}^{-1}$ are associated with $\mathrm{O}-\mathrm{C}=\mathrm{CH}$ sites on the furan ring, respectively, and are attributed to a heterocyclic aromatic compound, furan, indicating the presence of HMF aromatic rings [25]. Also, the stretching vibration between 1400 and $900 \mathrm{~cm}^{-1}$ indicates the C-C-H, C-O-H, and O-C-H of the furan ring [26]. This assures that the product obtained from corncob was HMF due to the confirmation of these regions as shown in Figure 5. 


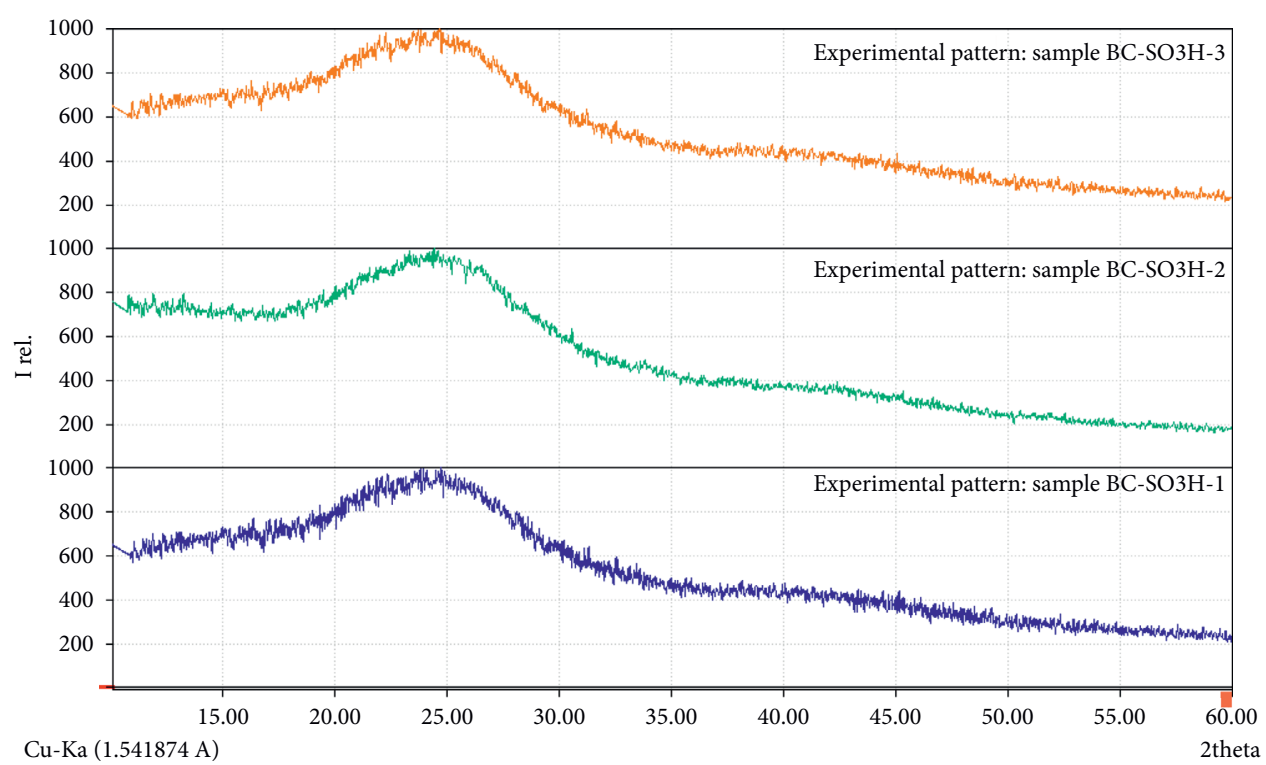

FIGURE 2: XRD pattern of catalyst prepared by (a) $98 \%$, (b) $96 \%$, and (c) $94 \% \mathrm{H}_{2} \mathrm{SO}_{4}$.

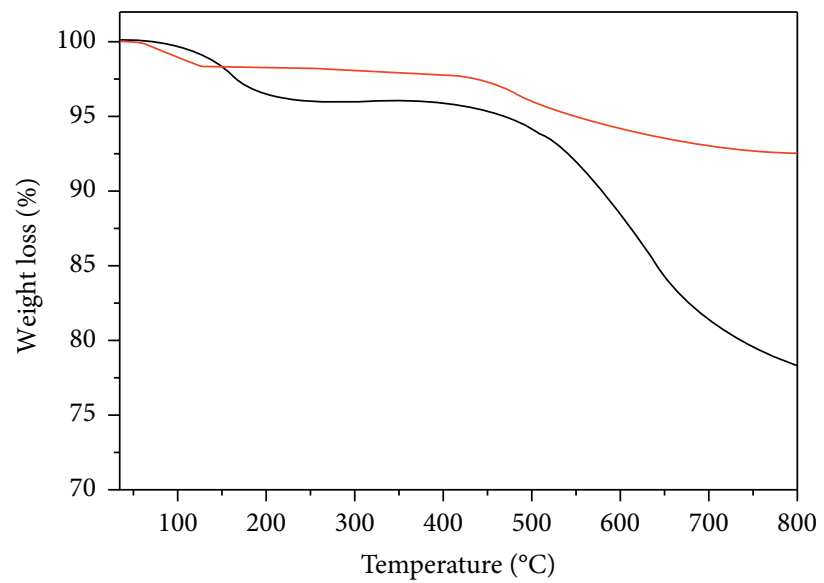

- Sulfonated catalyst

_ Nonsulfonated carbon

FIGURE 3: Thermogravimetric analysis (TGA) for catalyst from bamboo wood powder carbonized at $450^{\circ} \mathrm{C} \mathrm{BC}-0$ and after sulfonation (BC$\left.\mathrm{SO}_{3} \mathrm{H}_{-1}\right)$.

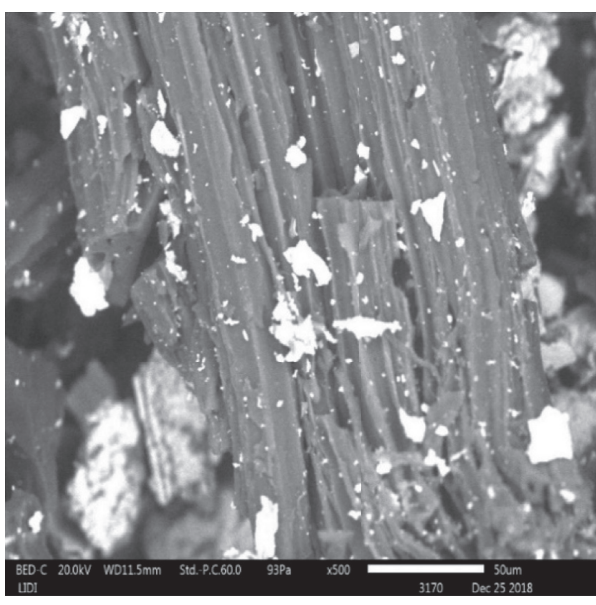

(a)

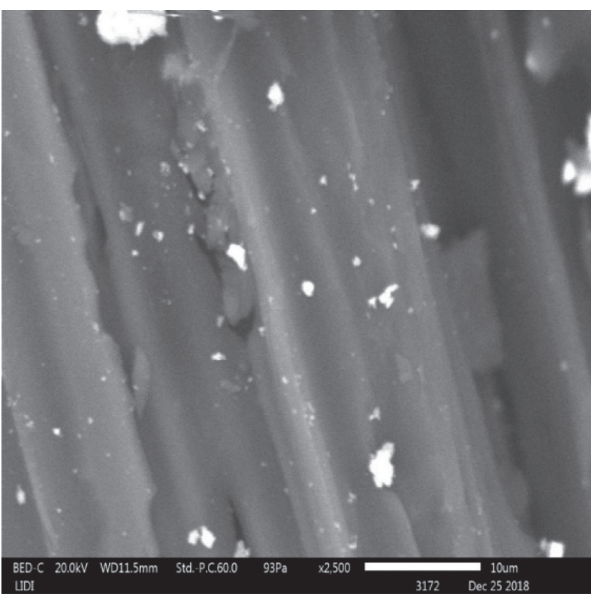

(b)

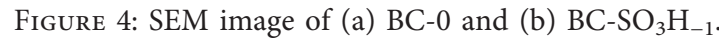




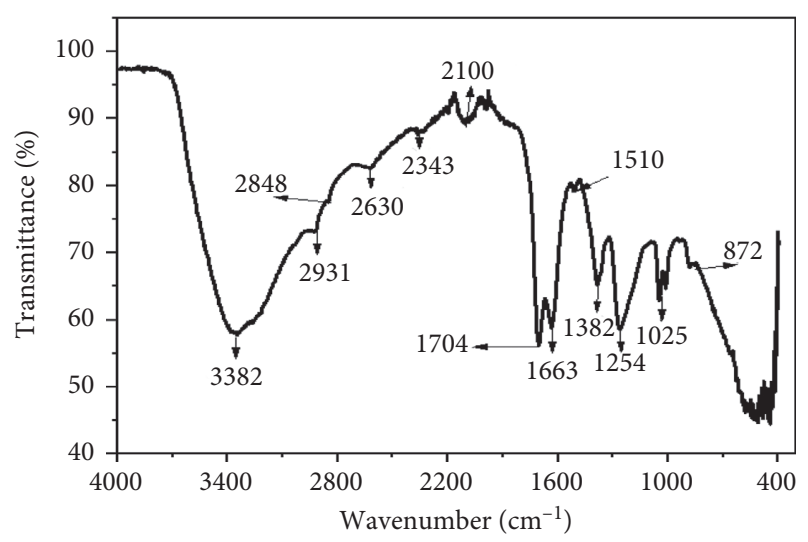

FIGURE 5: Characterization results of the intermediate product using FTIR.

\section{Conclusion}

Corncob had been successfully used as potential raw material for 5-HMF synthesis. The synthesis of 5-HMF was conducted in hydrolysis-dehydration reaction conditions with the presence of acid modified bamboo wood carbon catalyst. The reaction was intensified with water-ethyl acetate as a biphasic solvent by addition of $\mathrm{NaCl}$ in the reaction medium for the purpose of creating an interface between the organic and water phases. The catalyst was synthesized from bamboo with zinc chloride as textural promoter and resulted in high acid density carbon-based catalyst using a pyrolysis and sulfonation method. Structural study through elemental analysis and FTIR spectroscopy suggests that biochar-based catalyst consists of polycyclic aromatic carbon sheets bearing three different acidic groups of phenolic $(\mathrm{OH})$, carboxylic $(\mathrm{COOH})$, and sulfonic $\left(\mathrm{SO}_{3} \mathrm{H}\right)$, and the catalyst is stable up to temperature of $465^{\circ} \mathrm{C}$. In general, with increasing sulfuric acid concentration, the total acid density of the catalyst also increases due to high availability of sulfonic group.

\section{Data Availability}

All the necessary information required for replication of this work and/or conducting secondary analysis is included within the article.

\section{Conflicts of Interest}

The authors declare that they have no conflicts of interest.

\section{Acknowledgments}

The authors would like to thank the advisor Dr. Nigus Gabbiye for his guidance, advice, and encouragement in the course of this study. The authors would like to acknowledge Bahir Dar Institute of Technology and especially the staff of the Faculty of Chemical and Food Engineering for their positive approach and willingness to guide when challenges and difficulties are faced by them. In addition, the authors would like to express their gratitude to all lab technicians, especially lab technicians of Faculty of Chemical and Food
Engineering. The authors also gratefully thank Bahir Dar University, Department of Industrial Chemistry, and Chemistry Staff members for their support of ideas and materials.

\section{References}

[1] A. A. Rosatella, S. P. Simeonov, R. F. M. Frade, and C. A. M. Afonso, "5-hydroxymethylfurfural (HMF) as a building block platform: biological properties, synthesis and synthetic applications," Green Chemistry, vol. 13, no. 4, pp. 754-793, 2011.

[2] L. Hu, L. Lin, and S. Liu, "Chemoselective hydrogenation of biomass-derived 5-hydroxymethylfurfural into the liquid biofuel 2,5-dimethylfuran," Industrial \& Engineering Chemistry Research, vol. 53, no. 24, pp. 9969-9978, 2014.

[3] J.-J. Lu and W.-H. Chen, "Product yields and characteristics of corncob waste under various torrefaction atmospheres," Energies, vol. 7, no. 1, pp. 13-27, 2013.

[4] Y. Wang, H. Song, L. Peng, Q. Zhang, and S. Yao, "Recent developments in the catalytic conversion of cellulose," Biotechnology \& Biotechnological Equipment, vol. 28, no. 6, pp. 981-988, 2014.

[5] S. Dutta, S. De, M. I. Alam, M. M. Abu-Omar, and B. Saha, "Direct conversion of cellulose and lignocellulosic biomass into chemicals and biofuel with metal chloride catalysts," Journal of Catalysis, vol. 288, pp. 8-15, 2012.

[6] H. Li, A. Deng, J. Ren et al., "Catalytic hydrothermal pretreatment of corncob into xylose and furfural via solid acid catalyst," Bioresource Technology, vol. 158, pp. 313-320, 2014.

[7] D. E. Resasco, S. Sitthisa, J. Faria, T. Prasomsri, and M. Ruiz, "Furfurals as chemical platform for biofuels production," in Solid Waste as a Renewable Resource: Methodologies, p. 103, CRC Press, Boca Raton, FL, USA, 2011.

[8] Y.-B. Huang and Y. Fu, "Hydrolysis of cellulose to glucose by solid acid catalysts," Green Chemistry, vol. 15, no. 5, pp. 1095-1111, 2013.

[9] A. Hidayat, K. Rochmadi, K. Wijaya, and A. Budiman, "Esterification of free fatty acid on palm fatty acid distillate using activated carbon catalysts generated from coconut shell," Procedia Chemistry, vol. 16, pp. 365-371, 2015.

[10] C. D. Hartono, K. J. Marlie, J. N. Putro et al., "Levulinic acid from corncob by subcritical water process," International Journal of Industrial Chemistry, vol. 7, no. 4, pp. 401-409, 2016.

[11] A. I. Anukam, B. P. Goso, O. O. Okoh, and S. N. Mamphweli, "Studies on characterization of corn cob for application in a gasification process for energy production," Journal of Chemistry, vol. 2017, Article ID 6478389, 9 pages, 2017.

[12] S. Thangalazhy Gopakumar, Bio-oil Production through Fast Pyrolysis and Upgrading to "Green" Transportation Fuels, Auburn University, Auburn, Alabama, 2012.

[13] B. Lindman, G. Karlström, and L. Stigsson, "On the mechanism of dissolution of cellulose," Journal of Molecular Liquids, vol. 156, no. 1, pp. 76-81, 2010.

[14] A. Sluiter, B. Hames, R. Ruiz et al., Determination of Structural Carbohydrates and Lignin in Biomass. Laboratory Analytical Procedure, National Renewable Energy Laboratory, Denver, CO, USA, TP-510-42618, 2010.

[15] T.-M. Samuel, Bioethanol Fermentation of Corn Cob Using Immobilised Yeast Cells, Doctoral dissertation, WIReDSpace (Wits Institutional Repository on DSpace), Johannesburg, South Africa, 2012. 
[16] R. Kumar and N. Chandrashekar, "Fuel properties and combustion characteristics of some promising bamboo species in India," Journal of Forestry Research, vol. 25, no. 2, pp. 471-476, 2014.

[17] S. Yorgun, N. Vural, and H. Demiral, "Preparation of highsurface area activated carbons from paulownia wood by $\mathrm{ZnCl}_{2}$ activation," Microporous and Mesoporous Materials, vol. 122, no. 1-3, pp. 189-194, 2009.

[18] A. H. Abdullah, "Preparation and characterization of activated carbon from gelam wood bark (Melaleuca cajuputi)," Malaysian Journal of Analytical Sciences, vol. 7, no. 1, pp. 65-68, 2001.

[19] D. Lee, "Preparation of a sulfonated carbonaceous material from lignosulfonate and its usefulness as an esterification catalyst," Molecules, vol. 18, no. 7, pp. 8168-8180, 2013.

[20] X. Tong, Y. Ma, and Y. Li, "Biomass into chemicals: conversion of sugars to furan derivatives by catalytic processes," Applied Catalysis A: General, vol. 385, no. 1-2, pp. 1-13, 2010.

[21] F. Jamil, "Evaluation of synthesized green carbon catalyst from waste date pits for tertiary butylation of phenol," Arabian Journal of Chemistry, vol. 13, no. 1, 2017.

[22] X. Chen, Biomass Conversion and Upgrading over Carbon Catalyst, Nanyang Technological University, Singapore, 2018.

[23] B. S. Surendra and M. Veerabhadraswamy, "Microwave assisted synthesis of schiff base via bioplatform chemical intermediate (HMF) derived from jatropha deoiled seed cake catalyzed by modified bentonite clay," Materials Today: Proceedings, vol. 4, no. 11, pp. 11968-11976, 2017.

[24] N. Esmaeili, M. J. Zohuriaan-Mehr, H. Bouhendi, and G. Bagheri-Marandi, "HMF synthesis in aqueous and organic media under ultrasonication, microwave irradiation and conventional heating," Korean Journal of Chemical Engineering, vol. 33, no. 6, pp. 1964-1970, 2016.

[25] M. Zhang, H. Yang, Y. Liu, X. Sun, D. Zhang, and D. Xue, "First identification of primary nanoparticles in the aggregation of HMF," Nanoscale Research Letters, vol. 7, no. 1, p. 38, 2012.

[26] N. Esmaeili, M. J. Zohuriaan-Mehr, S. Mohajeri, K. Kabiri, and $\mathrm{H}$. Bouhendi, "Hydroxymethyl furfural-modified ureaformaldehyde resin: synthesis and properties," European Journal of Wood and Wood Products, vol. 75, no. 1, pp. 71-80, 2017. 